\title{
Protection of pancreatic $\beta$-cells by exendin-4 may involve the reduction of endoplasmic reticulum stress; in vivo and in vitro studies
}

\author{
Shin Tsunekawa, Naoki Yamamoto, Katsura Tsukamoto ${ }^{1}$, Yuji Itoh ${ }^{2}$, Yukiko Kaneko ${ }^{2}$, Toshihide Kimura ${ }^{2}$, \\ Yoh Ariyoshi, Yoshitaka Miura, Yutaka Oiso and Ichiro Niki
}

Department of Endocrinology and Diabetes, School of Medicine, Nagoya University, 65 Tsuruma-cho, Showa-ku, Nagoya 466-8550, Japan

${ }^{1}$ Central Research Laboratory, Sanwa Kagaku Kenkyusho Co. Ltd, 363 Shiosaki, Hokusei, Inabe, Mie 511-0406, Japan

${ }^{2}$ Department of Pharmacology, Oita University Faculty of Medicine, 1-1 Idaigaoka, Hasama, Yufu, Oita 879-5593, Japan

(Requests for offprints should be addressed to I Niki; Email: niki@med.oita-u.ac.jp)

\begin{abstract}
The aim of this study was to investigate the in vivo and in vitro effects of exendin-4, a potent glucagon-like peptide 1 agonist, on the protection of the pancreatic $\beta$-cells against their cell death. In in vivo experiments, we used $\beta$-cell-specific calmodulinoverexpressing mice where massive apoptosis takes place in their $\beta$-cells, and we examined the effects of chronic treatment with exendin-4. Chronic and s.c. administration of exendin-4 reduced hyperglycemia. The treatment caused significant increases of the insulin contents of the pancreas and islets, and retained the insulin-positive area. Dispersed transgenic islet cells lived only shortly, and several endoplasmic reticulum (ER) stress-related molecules such as immunoglobulin-binding protein (Bip), inositol-requiring enzyme-1 $\alpha, \mathrm{X}$-box-binding
\end{abstract}

protein-1 (XBP-1), RNA-activated protein kinase-like endoplasmic reticulum kinase, activating transcription factor-4, and $\mathrm{C} / \mathrm{EBP}-\mathrm{homologous}$ protein $(\mathrm{CHOP})$ were more expressed in the transgenic islets. We also found that the spliced form of XBP-1, a marker of ER stress, was also increased in $\beta$-cellspecific calmodulin-overexpressing transgenic islets. In the quantitative real-time PCR analyses, the expression levels of Bip and $\mathrm{CHOP}$ were reduced in the islets from the transgenic mice treated with exendin- 4 . These findings suggest that excess of ER stress occurs in the transgenic $\beta$-cells, and the suppression of ER stress and resultant protection against cell death may be involved in the anti-diabetic effects of exendin- 4 .

Journal of Endocrinology (2007) 193, 65-74

\section{Introduction}

The beneficial effects of glucagon-like peptide 1 (GLP-1) and its related substances such as inhibitors of dipeptidyl peptidase IV, its degrading enzyme, on the pancreatic $\beta$-cells have been reported; these agents enhance insulin release, increase (pro)insulin biosynthesis, promote $\beta$-cell development/ replication, and prevent $\beta$-cell exhaustion under the diabetic conditions (Drucker 2003, Leon et al. 2005). These effects are considered to result from an increase in the $\beta$-cell cAMP content (Thorens 1992), while cAMP-independent mechanisms of GLP-1 have also been suggested in other types of cells (Montrose-Rafizadeh et al. 1999).

Multiple pathways which cause $\beta$-cell damage have been suggested to participate in the pathogenesis of diabetes mellitus (Donath et al. 1999, Mandrup-Poulsen 2003, Scheuner et al. 2005). Among them, more attention has recently been directed to endoplasmic reticulum (ER) stress. ER stress is a series of cellular responses induced by several causes such as (over)production of misfolding proteins, disorder in $\mathrm{Ca}^{2+}$ dynamics in ER, oxidative stress, and exposure to cytokines. This process includes production of the chaperon proteins, translational attenuation, degradation

of the misfolding proteins, and eventual induction of apoptosis (Oyadomari et al. 2002a). A recent pathological study demonstrated that a decrease in the $\beta$-cell mass by apoptosis may occur in the human diabetic subjects (Butler et al. 2003). $\beta$-Cells are considered to be very sensitive to ER stress (Harding \& Ron 2002), and resultant apoptotic cell death was reported to occur in diabetic model animals (Oyadomari et al. 2002b).

Overexpression of calmodulin in the $\beta$-cell in vivo causes a sudden onset and persistent hyperglycemia without infiltration of lymphocytes (Epstein et al. 1989). We previously demonstrated that $\mathrm{Ca}^{2+}$-dependent apoptosis occurs in the $\beta$-cell and suggested that $\mathrm{Ca}^{2+} /$ calmodulin-dependent overexpression of nitric oxide may partially participate in the process (Yu et al. 2002). Recently, we have reported that the $\beta$-cell decay in this model was retarded by chronic administration of pituitary adenylate cyclase-activating polypeptides (PACAP), which increase cAMP production in the $\beta$-cell (Tsunekawa et al. 2005). We also suggested that the effect of PACAP mainly results from its protecting effect against a decrease in the $\beta$-cell mass.

In this paper, we examined the in vivo effects of exendin-4, a potent GLP-1 agonist, on the pancreatic $\beta$-cell in the 
$\beta$-cell-specific calmodulin-overexpressing transgenic (CaMTg) mice. We also investigated the underlying mechanism by which exendin- 4 protects $\beta$-cells from their apoptotic cell death.

\section{Materials and Methods}

\section{Production of transgenic animals}

CaMTg mice were kindly provided by Prof. A R Means (Duke University, Durham, NC, USA). The methods for production of this model have been described elsewhere (Epstein et al. 1989). Briefly, the rat insulin-II promoter/ chicken calmodulin cDNA chimeric gene was microinjected into mouse embryos derived from female FVBM mice, followed by the implantation of the embryos into pseudopregnant female FVBM mice. The transgenic mice were subsequently bred with the ICR strain (Yu et al. 2002). The progeny were housed in a temperature-, humidity-, and lightcontrolled room $\left(21-23^{\circ} \mathrm{C}, 12 \mathrm{~h}\right.$ light: $12 \mathrm{~h}$ darkness cycle, and free access to food and water). They were characterized as having blepharostenosis at 2-3 weeks and frank hyperglyce$\mathrm{mia}(>300 \mathrm{mg} / \mathrm{dl})$ with marked hypoinsulinemia at 4 weeks of age. In cases where earlier characterization was necessary, genomic typing was carried out (see below). Male CaMTg mice were bred with normal female ICR mice (Japan SLC, Hamamatsu, Japan) since the female CaMTg mice were almost infertile. The adult transgenic mice exhibited overt hyperphagia, polyposia, and polyuria, while they were only slightly lean. Unless otherwise mentioned, we used nontransgenic $(\mathrm{nTg})$ mice from the same litters as controls. This study has been approved by the Committees on Animal Experiments of Oita University and Nagoya University.
Genomic typing by PCR

Genomic DNA was extracted from the tails of the mice 7 days after birth using the QIAamp DNA Mini Kit (QIAGEN $\mathrm{GmBH}$ ) and was subjected to PCR amplification of the chicken calmodulin transgene. The specific primer pairs (Table 1) amplified a $200 \mathrm{bp}$ product only in the CaMTg mice. The results were confirmed by a comparison with the later phenotype of these mice such as blepharostenosis and hyperglycemia.

\section{In vivo treatment with exendin-4}

Exendin-4 was purchased from Sigma. Osmotic minipumps (model 1002, Alzet, Cupertino, CA, USA) were implanted in the midscapular region at the end of the second week after birth, and exendin-4 (10 $\mu \mathrm{g}$ per pump, equivalent to $\approx 28 \mathrm{nmol} /$ initial $\mathrm{kg} \mathrm{BW}$ per day) dissolved in saline was subcutaneously injected during the following 2 weeks. Saline was administered as a control. After the implantation, plasma glucose levels were measured daily using a compact glucose analyzer (MediSafe, Terumo, Tokyo, Japan). Blood samples were collected by tail cutting in the interval from 1000 to $1400 \mathrm{~h}$ from these mice fed ad libitum. The insulin concentrations in CaMTg serum taken from the canthus were often below the detectable range of the insulin ELISA employed here. Therefore, we took blood samples from the portal vein under anesthesia to determine the serum insulin concentrations. At the end of the experimental period, the pancreata were removed and weighed. For the measurement of the pancreatic insulin content, the pancreata were homogenized in ice-cold acid-ethanol solution $(0 \cdot 18 \mathrm{M}$ $\mathrm{HCl}$ in $75 \%$ ethanol) and centrifuged. The supernatants

Table 1 Sequences of the PCR primers used in this study, their accession numbers and the sizes of the amplified bands

\section{Accession number}

Gene

Primers for genomic typing by PCR Calmodulin DR413558

Primers for RT-PCR

\begin{tabular}{|c|c|}
\hline - -5 & \\
\hline Bip & AJ002387 \\
\hline$I R E-1 \alpha$ & AF071777 \\
\hline$X B P-1$ & BC029197 \\
\hline PERK & NM_01012 \\
\hline ATF-4 & NM_00971 \\
\hline CHOP & X67083 \\
\hline GAPDH & NM_00808 \\
\hline rimers for real-tim & PCR \\
\hline Spliced of XBP-1 & AF443192 \\
\hline CHOP & X67083 \\
\hline Bip & AJ002387 \\
\hline GAPDH & NM_008 \\
\hline
\end{tabular}

Forward primer

5'-GAGCCACCATGGCTGATCA-3'
5'-GAAAGGATGGTTAATGATGCTGAG-3'
5'-TGGTCTCCTCTCGGGTTCCTG-3'
5'-TTCCTTACCAGCCTCCCTTT-3'
5'-CGCTGCTGCTGCTTCTGTTCCT-3'
5'-GAAACCTCATGGGTTCTCCA-3'
5'-TATGAGGATCTGCAGGAGGT-3'
5'-CTTCACCACCATGGAGAAGGC-3'
5'-GTCCGCAGCAGGTGCAG-3'
Double dye probe
5'-AGGGCCAACAGAGGTCACAC-3'
Double dye probe
5'-AGAACGGCCGCGTGG-3'
Double dye probe
5'-CTTCACCACCATGGAGAAGGC-3'
Double dye probe

Reverse primer

Size

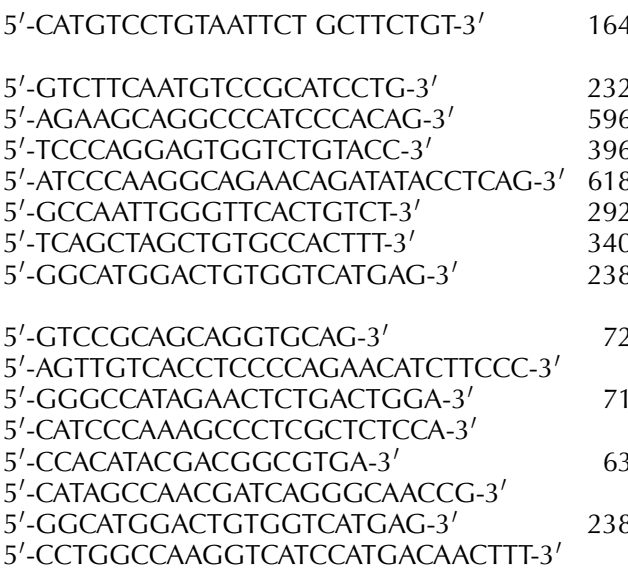

64

32 96

96 40 38 2 71 63 38 
were diluted and neutralized with Tris-buffered saline $(\mathrm{pH}$ 8.0) and subjected to ELISA using a commercialized kit (Shibayagi, Tokyo, Japan). For the histochemical studies, the pancreata were fixed in $4 \%$ paraformaldehyde in $0.1 \mathrm{M}$ phosphate buffer (pH 7•4).

\section{Insulin tolerance test}

After a $4 \mathrm{~h}$ fasting, human insulin (Humulin R, Eli Lilly) at $0 \cdot 25 \mathrm{U} / \mathrm{kg} \mathrm{BW}$ was intraperitoneally injected into exendin4 -treated or untreated mice at 4 weeks of age. Plasma glucose levels were then measured at $0,15,30$, and $45 \mathrm{~min}$ after the injection using a compact glucose analyzer.

\section{Measurement of the insulin content of isolated islets and determination of the survival rates of dispersed islet cells}

Pancreatic islets were isolated by collagenase digestion. The islet insulin content was measured after acid-ethanol extraction as described above. For the determination of the cell survival rate, isolated islets were dispersed by enzymatic digestion by dispase (Godo Shusei, Tokyo, Japan) and seeded onto a piece of poly-D-lysine-coated cover glass placed on a plastic dish. On the next day of the seeding, the cell number was counted under a phase-contrast microscope (MFA10100, Nikon, Tokyo, Japan) and was regarded as 100\% in each experimental group. The survival rate was expressed as a percentage of the numbers of the surviving cells at 48 and $72 \mathrm{~h}$ after seeding to the cell number at $24 \mathrm{~h}$.

\section{Immunofluorescence staining}

For the immunohistochemical study, the pancreata fixed in 4\% paraformaldehyde were sequentially washed thoroughly in PBS containing 10, 15, and 20\% sucrose. They were then embedded in optimal cutting temperature compound (Sakura, Tokyo, Japan) and frozen. The frozen sections were cut into $5 \mu \mathrm{m}$ thick slices and incubated for $1 \mathrm{~h}$ with anti-insulin guinea pig antibody (Seikagaku Kogyo, Tokyo, Japan) and anti-glucagon rabbit antibody (ZYMED, San Francisco, CA, USA). After washing with PBS, they were further incubated for $1 \mathrm{~h}$ in a mixture of rhodamine-conjugated anti-guinea pig IgG antibody (ICN, Costa Messa, CA, USA) and fluorescein isothiocyanate (FITC)-conjugated anti-rabbit IgG antibody (Vector, Burlingame, CA, USA). The sections were analyzed with a confocal scanning laser microscope (MR-1024, Japan Bio-Rad). Morphological analysis of the data was carried out by the NIH Image software.

\section{Expression of ER stress-related molecules in the isolated islets}

mRNA in the isolated islets was extracted, and the expression levels of several ER stress-related genes (glucose-regulated protein 78/immunoglobulin-binding protein (Bip), inositolrequiring enzyme-1 (IRE-1 $\alpha$ ), X-box-binding protein-1
(XBP-1), RNA-activated protein kinase-like endoplasmic reticulum kinase (PERK), activating transcription factor-4 (ATF-4), C/EBP-homologous protein (CHOP)) were examined by RT-PCR. The sequences of the specific primer pairs are described in Table 1.

For more quantitative analysis, real-time PCR was carried out. Three micrograms of total RNA, extracted from isolated islets using the Trizol reagent (Invitrogen-Life Technologies, Inc.), were reverse transcribed using transcriptor reverse transcriptase (Roche Molecular Biochemicals). After cDNA synthesis, quantitative real-time PCR was performed in $25 \mu \mathrm{l}$ reaction mixtures containing qPCR Mastermix (Eurogentec, Seraing, Belgium) using the $\mathrm{Mx} 3000 \mathrm{P}$ personal real-time PCR system (Stratagene Japan Co., Tokyo, Japan). Reaction mixtures were incubated for an initial denaturation at $95{ }^{\circ} \mathrm{C}$ for $10 \mathrm{~min}$, followed by 40 cycles, each cycle consisting of $95^{\circ} \mathrm{C}$ for $15 \mathrm{~s}$ and $60{ }^{\circ} \mathrm{C}$ for $1 \mathrm{~min}$. The primers and probes of the spliced form of XBP-1, Bip, CHOP, and glyceraldehyde3-phosphate dehydrogenase (GAPDH) were from Nippon EGT Co. Ltd (Toyama, Japan). Expression levels of spliced XBP-1, Bip, and CHOP mRNAs were standardized by comparison with that of GAPDH. The sequences of the specific primer pairs are described in Table 1. The specificity of each primer and probe set was confirmed by visualization of a single PCR product by agarose gel electrophoresis.

\section{Statistical analysis}

The data were expressed as the mean \pm s.E.M. The statistical significance was estimated by Student's $t$-test or one-way ANOVA, followed by post hoc Bonferroni. A $P$ value $<0 \cdot 05$ was considered statistically significant.

\section{Results}

Effects of chronic administration of exendin-4 on hyperglycemia in the CaMTg mice

CaMTg mice showed an acute and progressive hyperglycemia at 21 days after birth and thereafter. Chronic and s.c. administration of exendin-4 reduced hyperglycemia in CaMTg mice, whereas it did not show any effect on the plasma glucose level in $\mathrm{nTg}$ mice (Fig. 1). The exendin-4 treatment did not change BW in both $\mathrm{nTg}$ and CaMTg mice $(25 \cdot 8 \pm 0 \cdot 5$ vs $25 \cdot 3 \pm 0 \cdot 4 \mathrm{~g}$ for $\mathrm{nTg}$ mice without and with exendin-4 respectively and $25 \cdot 0 \pm 0.7$ vs $24 \cdot 4 \pm 0.6 \mathrm{~g}$ for CaMTg mice without and with exendin-4 respectively at 4 weeks of age, $n=5-12$ ). We also found that the food intake, when assessed at 4 weeks of age, was unchanged by the exendin-4 treatment (data not shown).

\section{Insulin tolerance test}

Since some GLP-1-related agents have been reported to improve insulin sensitivity (Gedulin et al. 2005), we estimated the effects 


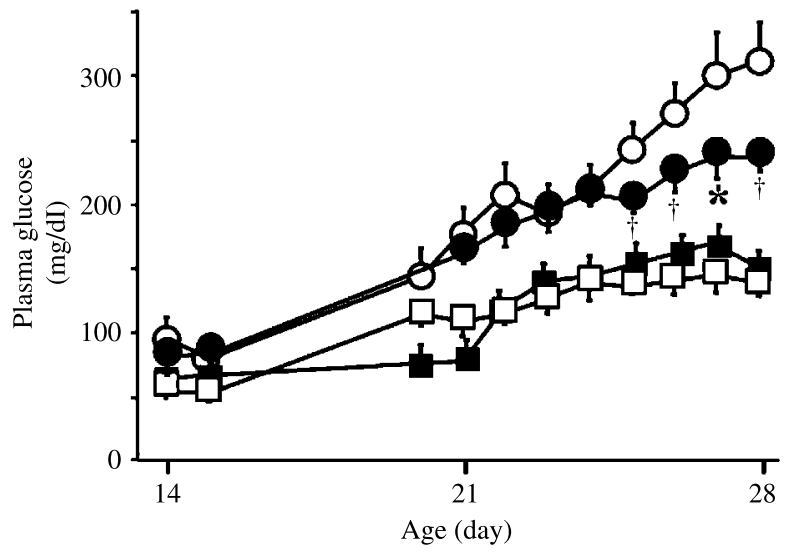

Figure 1 Daily profiles of plasma glucose levels in nTg and CaMTg mice treated with exendin-4 or saline. Exendin-4

(28 nmol/initial kg BW per day) was given subcutaneously and continuously over 2 weeks through osmotic minipumps transplanted on day 14 after birth. Blood samples were taken daily by tail cutting, and plasma glucose levels were measured using a compact glucose analyzer. Open circles, CaMTg mice treated with saline $(n=21)$. Closed circles, CaMTg mice treated with exendin-4 $(n=13)$. Open squares, nTg mice treated with saline $(n=13)$. Closed squares, nTg mice treated with exendin- 4 $(n=7)$. Each symbol represents a mean + S.E.M. value. ${ }^{*} P<0 \cdot 05$, ${ }^{+} P<0 \cdot 01$, as compared with the corresponding value in the saline-treated CaMTg mice.

of exendin-4 on the insulin sensitivity. As illustrated in Fig. 2, time-dependent decreases in the plasma glucose concentrations after insulin injection $(0 \cdot 25 \mathrm{U} / \mathrm{kg} \mathrm{BW}$ i.p.) were observed in all groups. Although the glucose levels at time 0 were different, we could not find any difference in the decline between exendin-4treated and untreated CaMTg or $\mathrm{nTg}$ mice.

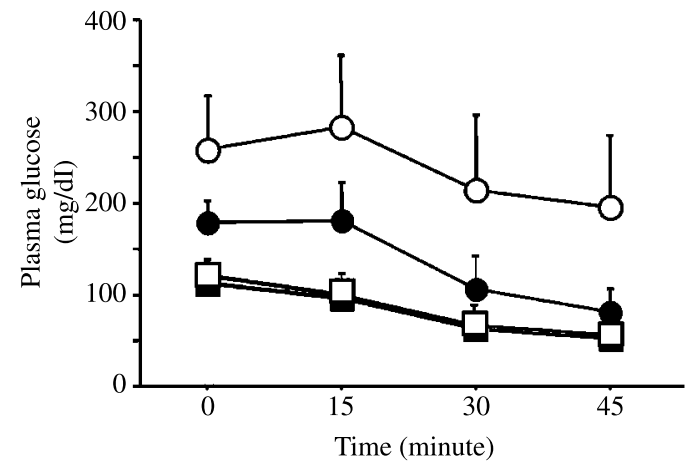

Figure 2 Lack of effects of the exendin-4 treatment on the insulin tolerance test. After the 2-week in vivo treatment with or without exendin-4, human insulin $(0 \cdot 25 \mathrm{U} / \mathrm{kg} \mathrm{BW})$ was injected intraperitoneally. The plasma glucose concentrations were measured at 0 , 15, 30, and $45 \mathrm{~min}$. Open circles, CaMTg mice treated with saline. Closed circles, CaMTg mice treated with exendin-4. Open squares, $\mathrm{nTg}$ mice treated with saline. Closed squares, nTg mice treated with exendin-4. Each symbol represents a mean \pm S.E.M. value; $n=5$.
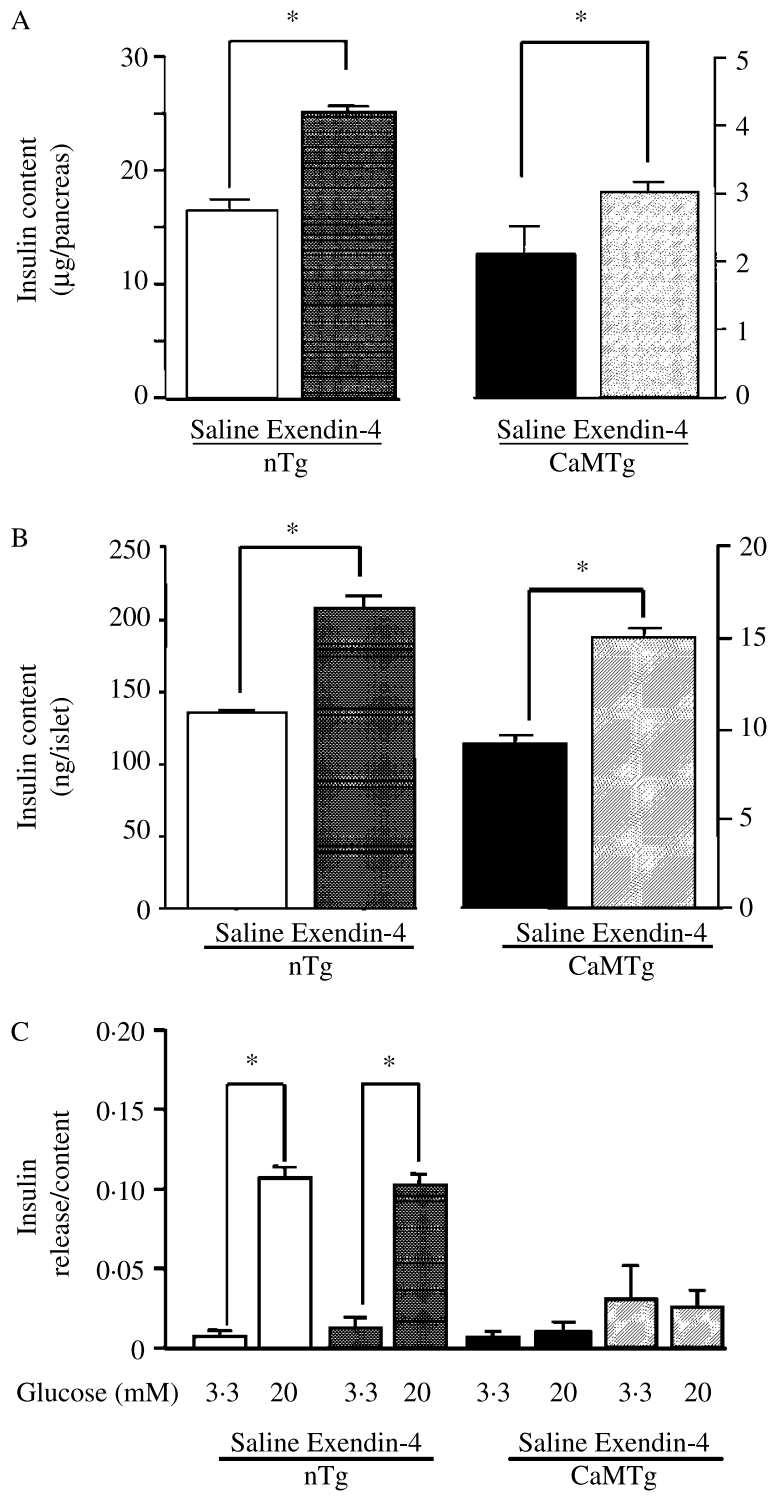

Figure 3 Effects of exendin-4 treatments on the insulin contents of the pancreata and islets and on insulin release. (A) At the end of the 2-week administration of exendin-4, pancreata from the salinetreated $\mathrm{nTg}(n=6$, open column), the exendin-4-treated $\mathrm{nTg}(n=3$, shaded column), the saline-treated CaMTg ( $n=4$, closed column), and the exendin-4-treated CaMTg mice ( $n=8$, hatched column) were homogenized in ice-cold acid-ethanol solution and centrifuged. The supernatants were subjected to ELISA for insulin determination. (B) On day 28 after birth, groups of three pancreatic islets isolated from the saline-treated $\mathrm{nTg}(n=24$, open column), the exendin-4-treated $\operatorname{nTg}(n=8$, shaded column), the saline-treated CaMTg ( $n=25$ closed column), and the exendin-4-treated CaMTg mice ( $n=7$, hatched column) were extracted. Their insulin content was measured and expressed as ng/islet. (C) Insulin release from isolated islets was measured by the batch incubation for $30 \mathrm{~min}$ with basal $(3 \mathrm{mM})$ or stimulatory $(20 \mathrm{mM})$ glucose. Released insulin was expressed as a rate of release to the islet insulin content. Each column represents a mean \pm S.E.M. value. ${ }^{*} P<0 \cdot 05 ; n=5$. 
Effects of the exendin-4 treatment on the serum insulin concentrations

The serum insulin concentrations were not altered by the exendin-4 treatment both in $\mathrm{nTg}$ and CaMTg mice fed ad libitum (data not shown). We found that the exendin-4 treatment increased the serum insulin concentrations taken at 15 min after i.p. injection of glucose $(2 \mathrm{~g} / \mathrm{kg} \mathrm{BW})$ in $\mathrm{nTg}$ and CaMTg mice to a certain extent, although they did not reach statistical significance $(2 \cdot 88 \pm 0 \cdot 78$ and $3 \cdot 38 \pm 0 \cdot 85 \mathrm{ng} / \mathrm{ml}$ for $\mathrm{nTg}$ mice without and with the exendin-4 treatment respectively and $0.42 \pm 0.15$ and $1.54 \pm 0.79 \mathrm{ng} / \mathrm{ml}$ for CaMTg mice without and with the exendin-4 treatment respectively, $n=3-5)$.
Effects of the in vivo treatment with exendin-4 on the pancreatic insulin content

Figure 3 shows the effects of the exendin-4-treatment on the insulin contents in the pancreas and pancreatic islets. The CaMTg pancreatic insulin content was decreased to $11 \cdot 8 \%$ of the nTg control (Fig. 3A) and the CaMTg islet insulin content was also decreased to $6.7 \%$ of the control (Fig. 3B) at the end of 4 weeks after birth. Chronic treatment with exendin-4 resulted in significant increases in the pancreatic insulin contents in both $\mathrm{nTg}$ and $\mathrm{CaMTg}$ mice (Fig. 3A). The treatment also increased the insulin content of isolated islets from $\mathrm{nTg}$ and CaMTg mice (Fig. 3B). In insulin secretion experiments using isolated
A
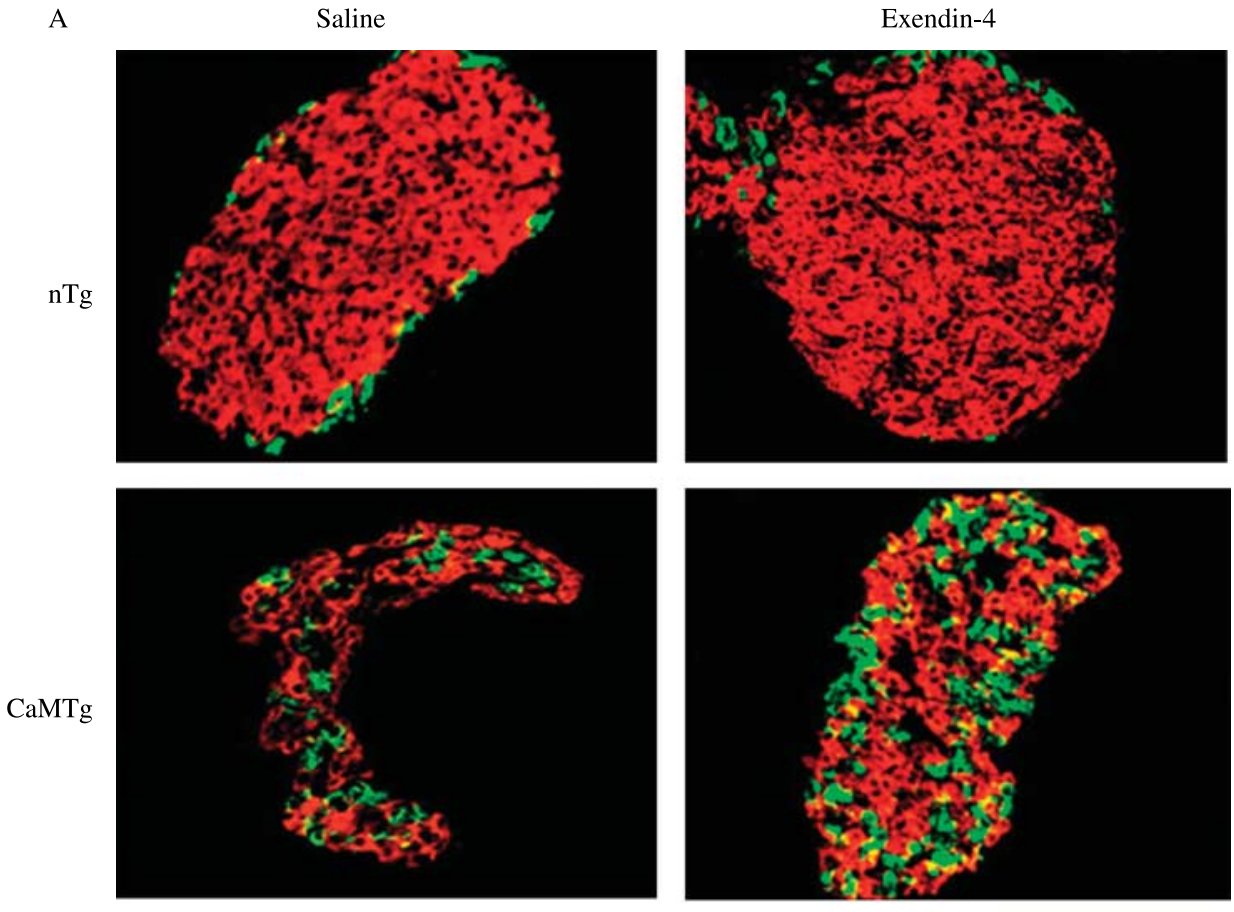

B

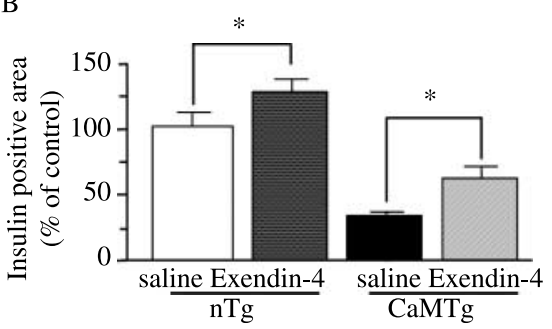

Figure 4 In vivo effects of exendin-4 on the insulin-positive area. (A) Mouse pancreata at 4 weeks of age were immunostained with anti-insulin and anti-glucagon antibodies and visualized by the FITC-and rhodamine-conjugated second antibodies respectively. Bar $=100 \mu \mathrm{m}$. (B) Morphometrical analyses were carried out for 30-80 islets per pancreas from 3 to 5 mice for each group to measure the insulinpositive areas. Each column represents a mean \pm S.E.M. value for the saline-treated $n T g$ (open column), the exendin-4-treated nTg (shaded column), the saline-treated CaMTg (closed column), and the exendin-4-treated CaMTg islets (hatched column). ${ }^{*} P<0 \cdot 05$. 
islets, glucose stimulation failed to increase insulin secretion from untreated CaMTg islets. The treatment did not ameliorate the unresponsiveness, but it increased the rate of released insulin to the level of the insulin content required for basal glucose (Fig. 3C).

Influence of the exendin-4 treatment in the insulin-positive area

The above effects of the exendin-4 treatment on the insulin contents led us to an idea that the treatment may expand the $\beta$-cell insulin-positive area in individual islets. Immunohistochemical approach showed an increase in the insulin-positive areas in the $\mathrm{nTg}$ or CaMTg islets treated with exendin-4 (Fig. 4A). Indeed, quantitative morphological analysis suggested that the insulin-positive areas in individual islets were significantly increased by the exendin- 4 treatment both in the $\mathrm{nTg}$ and CaMTg mice (Fig. 4B). The spatial derangement of the CaMTg islet endocrine cells was, however, unchanged by the treatment with exendin-4 (Fig. 4A). When estimated by 5-bromo-2'-deoxyuridine staining, we could not find any effect of the exendin- 4 treatment on $\beta$-cell replication in $\mathrm{CaMTg}$ mice (data not shown).

\section{Survival rate of the $n \mathrm{Tg}$ and CaMTg islet cells}

In our preliminary experiments, normal islet cells survived well in the presence of $11.1 \mathrm{mM}$ glucose, which agrees with previous report (Efanova et al. 1998). With 11.1 mM glucose, the life span for CaMTg islet cells was very short; $\approx 60 \%$ of the cells disappeared during the observation from 24 to $72 \mathrm{~h}$ after seeding (Fig. 5).

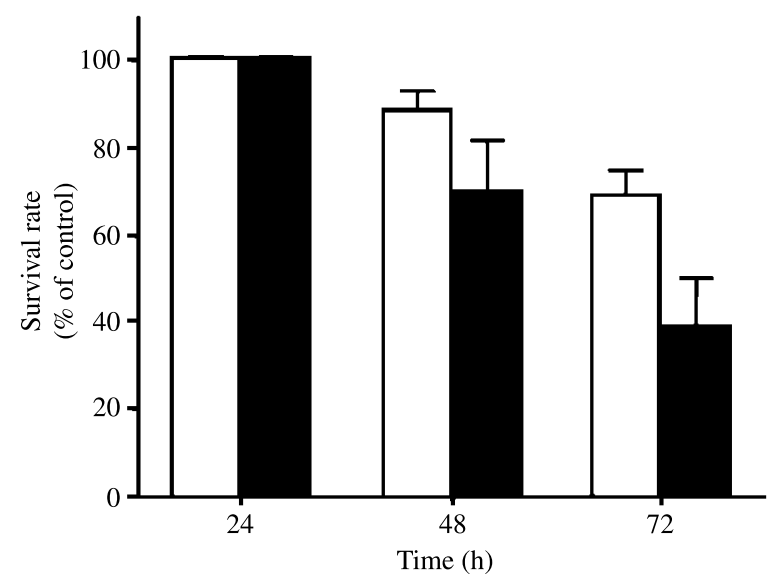

Figure 5 Survival rate of the dispersed islet cells. Dispersed cells obtained from nTg (open columns) and CaMTg islets (closed columns) were seeded onto a plastic dish, and cultured for 3 days. The survival rates were expressed as a percentage of the surviving cells over the cells at $24 \mathrm{~h}$ after seeding. Each symbol represents a mean \pm S.E.M. value for $4-5$ observations.
Expression of ER stress-related molecules in CaMTg islets

We examined expression levels of the ER stress-related molecules (Bip, IRE-1 $\alpha, \mathrm{XBP}-1, \mathrm{PERK}, \mathrm{ATF}-4$, and $\mathrm{CHOP}$ ) in $\mathrm{nTg}$ and $\mathrm{CaMTg}$ islets at 4 weeks of age by RT-PCR. As illustrated in Fig. 6A, all these ER stressresponse genes were more expressed in CaMTg islets. To confirm the induction of ER stress in CaMTg islets, we further carried out quantitative real-time PCR analysis for the spliced form of XBP1 mRNA and found the XBP1 splicing was indeed increased in CaMTg islets $(764 \pm 236 \%$ of the expression level in the saline-treated $\mathrm{nTg}$ islets; Fig. 6B). These findings suggest that CaMTg islets were exposed to increased ER stress.

Quantitative estimation of Bip and CHOP expression levels by real-time PCR

Among these ER stress-related molecules, we quantified expression levels of Bip and CHOP by quantitative real-time PCR and estimated the effects of the exendin-4 treatment on the expression levels. We estimated these expression levels as a rate to the GAPDH expression, and found Bip and CHOP were more expressed in the CaMTg islets (1682 \pm 412 and $9600 \pm 1370 \%$ of each expression level in the saline-treated $\mathrm{nTg}$ islets for Bip and CHOP respectively, $n=3)$. The in vivo treatment with exendin-4 significantly lowered the expression levels of both genes in the CaMTg islets (396 \pm 201 and $3816 \pm 956 \%$ of each expression level in the saline-treated $n T g$ islets for Bip and CHOP respectively, $n=3$; Fig. 7).

\section{Discussion}

Exendin-4 is a homolog of GLP-1 originally derived from Heloderma suspectum and known to possess a potent antidiabetic effect through its binding to the GLP-1 receptor (Eng et al. 1992). The present study demonstrated that the beneficial effects of exendin-4 were also found in CaMTg diabetic mice, and that its major effect was to maintain the $\beta$-cell mass, because 1) the exendin-4 treatment increased the insulin contents of the pancreas and islets and 2) it also expanded the insulin-positive area in both nTg and CaMTg mice. Although the extrapancreatic effects of GLP-1 have been reported to participate in the hypoglycemic effects of exendin-4 (Egan et al. 1994, Luque et al. 2002, Dardevet et al. 2004), we could not find any effect of the treatment on plasma glucose levels in the insulin tolerance test.

Anti-apoptotic effects of the long-acting GLP-1 analog, liraglutide, have also been reported with primary-cultured neonatal rat $\beta$-cells, and such effects were reproduced by the adenylate cyclase activator, forskolin (Bregenholt et al. 2005). We could not find any effect of the exendin-4 treatment on $\beta$-cell replication. Since similar results were obtained by chronic administration of PACAP to CaMTg mice (Tsunekawa et al. $2005)$, we suggest that cAMP production may protect $\beta$-cells 
A
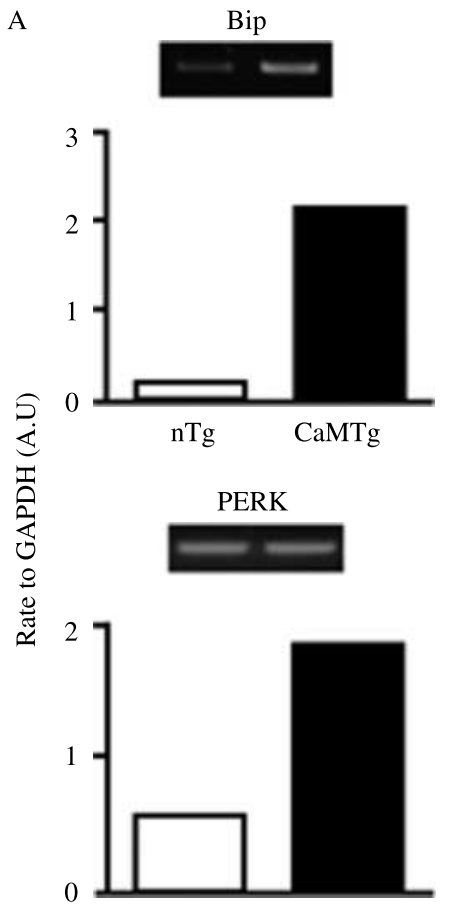

$\mathrm{nTg}$

CaMTg
$\operatorname{IRE} 1 \alpha$
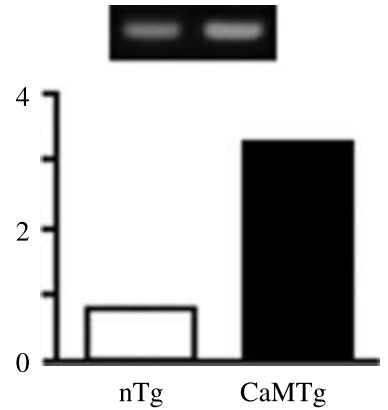

ATF-4

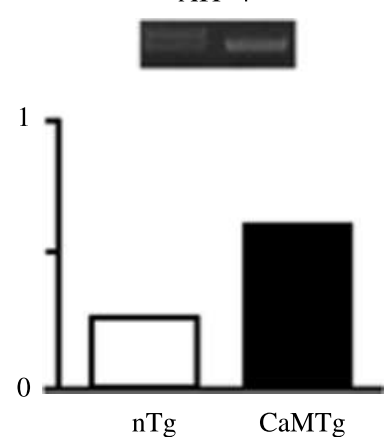

XBP-1

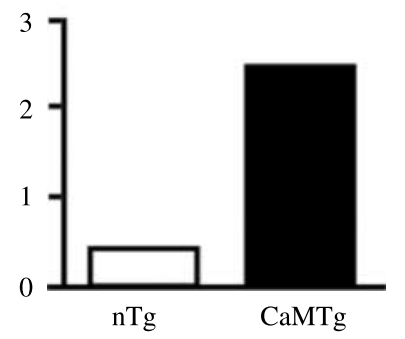

CHOP

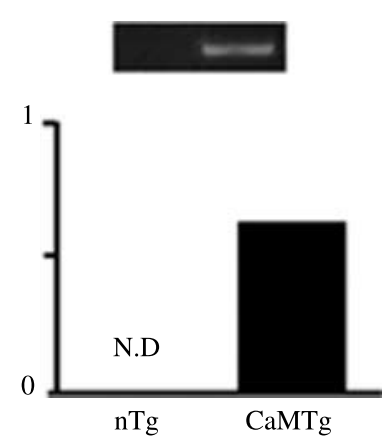

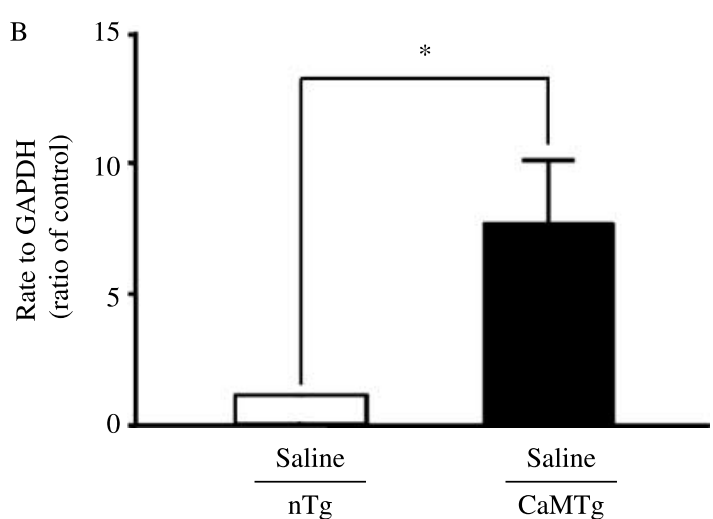

Figure 6 Expression levels of ER stress-related molecules by RT-PCR (A) and expression levels of the spliced form of XBP-1 by real-time PCR (B) in CaM transgenic islets. The expression levels of the ER stress-related molecules in mRNA extracted from nTg (open columns) and CaMTg (closed columns) islets were examined by RT-PCR (A) and the expression levels of the spliced form of XBP-1 by real-time PCR (B). Data were expressed as the rates to the expression levels to GAPDH in the same sample. For Fig. $6 \mathrm{~A}$, these results are the representative of three experiments with similar results. Statistical significance in Fig. 6B was assessed by Student's $t$-test. $* P<0 \cdot 05 ; n=3$. N.D, not determined; A.U, arbitrary units.

against apoptotic cell death in the diabetic mice. One difference between the PACAP and exendin-4 effects on CaMTg mice is the absence of the effects of PACAP on $\mathrm{nTg}$ mice. We do not know why the in vivo treatment with exendin-4 expanded the insulin-positive area in both $\mathrm{nTg}$ and CaMTg mice, whereas that with PACAP only improved the latter (Tsunekawa et al. 2005).

A few possible mechanisms of $\beta$-cell protection by GLP-1 or exendin-4 have also been reported. Reduction of caspase- 3 expression in islets by GLP-1 has been proposed in a diabetic model animal (Wang \& Brubaker 2002). Jhala et al. (2003) reported that GLP-1 may exhibit its protective effects through the activation of protein kinase B/Akt through cAMPdependent phosphorylation of cAMP-responsive elementbinding protein and resultant activation of the insulin signaling. A recent study using insulin receptor substrate-2 (IRS-2) knockout mice demonstrated that $\beta$-cell protection by GLP-1 required the IRS-2 signaling (Park et al. 2006). 
A
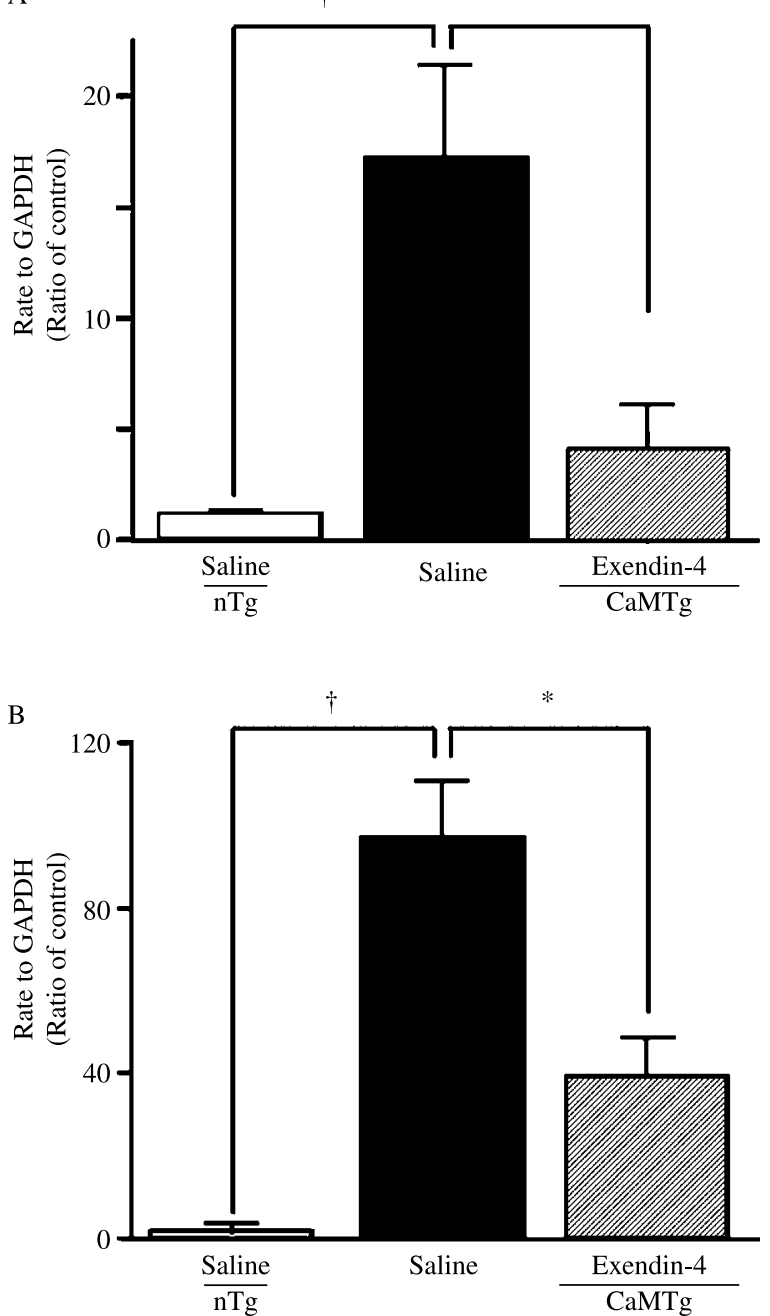

Figure 7 Effects of the in vivo exendin-4 treatment on Bip and CHOP expression levels estimated by quantitative real-time PCR. mRNA was extracted from saline-treated $\mathrm{nTg}$ islets (open column), saline-treated CaMTg islets (closed column), and exendin-4-treated CaMTg islets (hatched column) at 4 weeks of age. The expression levels of Bip (A) and CHOP (B) were evaluated by quantitative realtime PCR. Data were expressed as the rates to that of GAPDH in the same sample. Each column represents a mean \pm S.E.M. value for three independent experiments. ${ }^{*} P<0 \cdot 05 ;{ }^{\dagger} P<0 \cdot 01 ; n=3$.

We further investigated the underlying mechanism of the $\beta$-cell protection by exendin- 4 in this study and found that several genes related to ER stress were highly expressed cells as well as the increase of XBP-1 splicing in CaMTg islets. Among them, elevated expression levels of Bip and CHOP in the CaMTg $\beta$-cells were reduced by the in vivo exendin-4 treatment. It implies that the apoptotic process in the transgenic islet cells may involve excess of ER stress, and exendin-4 may lessen the ER stress and prevent $\beta$-cell apoptosis in the transgenic $\beta$-cells.
The reason why calmodulin overexpression in the $\beta$-cells induces $\beta$-cell death remains unclear. It was previously reported that, among the 13 proteins overexpressed in $\beta$-cells using the insulin promoter in vivo, only calmodulin and major histocompatibility complex molecules produced early onset diabetes (Harrison et al. 1989). One possibility is that calmodulin overexpression per se may trigger ER stress in CaMTg mice. We previously measured the calmodulin content in the islets in this model $(1 \cdot 3$ and $2 \cdot 1 \mathrm{ng}$ /islet for $\mathrm{nTg}$ and CaMTg mice respectively; Yu et al. 2002). When we standardized these values by their pancreatic insulin content at this age (Tsunekawa et al. 2005), $\approx 4.9$ times overexpression of calmodulin was achieved by the gene targeting. The overexpression rate is relatively not very high, but if we consider a fairly high concentration of calmodulin in the intact islets (Sugden et al. 1979, Valverde \& Malaisse 1984), we speculate that overexpressed calmodulin itself may be a cause of ER stress in the CaMTg $\beta$-cells.

Since inhibition of the $\mathrm{Ca}^{2+}$ influx prevented high glucose-induced apoptosis of the $\beta$-cells (Efanova et al. 1998 ), one possibility is that exendin-4 may reduce $\mathrm{Ca}^{2+}$ influx into the $\beta$-cells by high glucose. However, the effects of exendin-4 or GLP-1 on the $\beta$-cell cytoplasmic $\mathrm{Ca}^{2+}$ concentration $\left(\left[\mathrm{Ca}^{2+}\right]_{\mathrm{i}}\right.$ ) seem to be complex. GLP-1 has been reported to lower glucose-induced $\left[\mathrm{Ca}^{2+}\right]_{\mathrm{i}}$ increase in rat $\beta$-cells (Yaekura et al. 1998). Protection by exendin-4 of $\beta$-cells from apoptotic cell death may, therefore, result from its decreasing effect on the intracellular $\mathrm{Ca}^{2+}$ levels. On the other hand, GLP-1 has also been reported to increase $\left[\mathrm{Ca}^{2+}\right]_{\mathrm{i}}$ through inhibition of the $\mathrm{K}_{\text {ATP }}$ channels in the mouse $\beta$-cells (Gromada et al. 1997) or through activation of $\mathrm{Ca}^{2+}$-induced $\mathrm{Ca}^{2+}$ release in INS-1 $\beta$ cells (Kang \& Holz 2003). We have to be careful in the interpretation of these results, because most of these studies are monitoring $\left[\mathrm{Ca}^{2+}\right]_{\mathrm{i}}$ during a short duration after application of GLP-1, and the chronic changes in $\left[\mathrm{Ca}^{2+}\right]_{\mathrm{i}}$ dynamics after its long-term treatment may be different.

Another possibility is that exendin-4 may act on the intraER $\mathrm{Ca}^{2+}$ dynamics. There is a line of evidence suggesting that ER stress is caused by intraER $\mathrm{Ca}^{2+}$ depletion. Some isoforms of the sarco(endo)plasmic reticulum $\mathrm{Ca}^{2+}$-ATPases (SERCA) have been expressed in the human and rodent $\beta$-cells (Roe et al. 1994, Varadi et al. 1996). Inhibition of SERCA is known to cause apoptotic cell death in the MIN6 $\beta$-cell (Zhou et al. 1998). It has recently been reported that cytokines which cause $\beta$-cell death downregulate SERCA2b, deplete intraER $\mathrm{Ca}^{2+}$, and induce ER stress (Cardozo et al. 2005). The expression levels of SERCA isoforms are lowered in $\mathrm{db} / \mathrm{db}$ diabetic mice and IRS-1 null mice (Roe et al. 1994 Kulkarni et al. 2004). In a genetic approach, the UK prospective diabetes study suggests that sequence variants of SERCA3 are involved in the genetic etiology of Caucasian type 2 diabetes mellitus (Varadi et al. 1999). GLP-1, as well as the adenylate cyclase activator forskolin and the membrane-permeable cAMP analog dibutylyl cAMP, is known to increase $\mathrm{Ca}^{2+}$ uptake to ER 
through activation of $\mathrm{ER} \mathrm{Ca}^{2+}$ pump in the $\beta$-cell (Yaekura \& Yada 1998). Therefore, exendin-4 may reduce ER stress through activating the ER $\mathrm{Ca}^{2+}$-pump and increasing $\mathrm{Ca}^{2+}$ uptake into ER. Interestingly, cAMP-dependent phosphorylation of phospholamban has been reported to activate sarco(endo)plasmic reticulum $\mathrm{Ca}^{2+}$ pump in endothelial cells (Schildberg et al. 2005).

Very recently, it has been demonstrated that in vivo treatment with exendin-4 reduced the expression of ER-stress markers in the islets from $\mathrm{db} / \mathrm{db}$ diabetic mice (Yusta et al. 2006). Our present findings also support their finding and further suggests that the GLP-1 agonist may be useful for the maintenance of the $\beta$-cells and prevent $\beta$-cell exhaustion under diabetic conditions.

\section{Acknowledgements}

The authors are grateful to Prof. A R Means (Duke University, Durham, NC, USA) for his generous gift of CaMTg mice. This work was supported in part by two Grants-in-Aid for Scientific Research (Nos. 13671183 and 13470006) from the Japan Society for the Promotion of Science, a research grant from the Japan Insulin Study Group, a grant from the Research for the Future Program of the Japan Society for the Promotion of Science (JSPS-RFTF97I00201) and by grants from the Japan Research Foundation for Clinical Pharmacology, and from the Suzuken Memorial Foundation. A part of this work was also supported by Butterfield Awards for UK-Japan collaboration in medical research and public health practice. The authors declare that there is no conflict of interest that would prejudice the impartiality of this scientific work.

\section{References}

Bregenholt S, Moldrup A, Blume N, Karlsen AE, Nissen Friedrichsen B, Tornhave D, Knudsen LB \& Petersen JS 2005 The long-acting glucagonlike peptide-1 analogue, liraglutide, inhibits beta-cell apoptosis in vitro. Biochemical and Biophysical Research Communications 330 577-584.

Butler AE, Janson J, Bonner-Weir S, Ritzel R, Rizza RA \& Butler PC 2003 Beta-cell deficit and increased beta-cell apoptosis in humans with type 2 diabetes. Diabetes 52 102-110.

Cardozo AK, Ortis F, Storling J, Feng YM, Rasschaert J, Tonnesen M, Van Eylen F, Mandrup-Poulsen T, Herchuelz A \& Eizirik DL 2005 Cytokines downregulate the sarcoendoplasmic reticulum pump $\mathrm{Ca}^{2+}$ ATPase $2 \mathrm{~b}$ and deplete endoplasmic reticulum $\mathrm{Ca}^{2+}$, leading to induction of endoplasmic reticulum stress in pancreatic beta-cells. Diabetes 54 452-461.

Dardevet D, Moore MC, Neal D, DiCostanzo CA, Snead W \& Cherrington AD 2004 Insulin-independent effects of GLP-1 on canine liver glucose metabolism: duration of infusion and involvement of hepatoportal region. American Journal of Physiology, Endocrinology and Metabolism 287 E75-E81.

Donath MY, Gross DJ, Cerasi E \& Kaiser N 1999 Hyperglycemia-induced beta-cell apoptosis in pancreatic islets of Psammomys obesus during development of diabetes. Diabetes 48 738-744.

Drucker DJ 2003 Glucagon-like peptides: regulators of cell proliferation, differentiation, and apoptosis. Molecular Endocrinology 17 161-171.
Efanova IB, Zaitsev SV, Zhivotovsky B, Kohler M, Efendic S, Orrenius S \& Berggren PO 1998 Glucose and tolbutamide induce apoptosis in pancreatic beta-cells. A process dependent on intracellular $\mathrm{Ca}^{2+}$ concentration. Journal of Biological Chemistry 273 33501-33507.

Egan JM, Montrose-Rafizadeh C, Wang Y, Bernier M \& Roth J 1994 Glucagon-like peptide-1(7-36) amide (GLP-1) enhances insulin-stimulated glucose metabolism in 3T3-L1 adipocytes: one of several potential extrapancreatic sites of GLP-1 action. Endocrinology 135 2070-2075.

Eng J, Kleinman WA, Singh L, Singh G \& Raufman JP 1992 Isolation and characterization of exendin-4, an exendin-3 analogue, from Heloderma suspectum venom. Further evidence for an exendin receptor on dispersed acini from guinea pig pancreas. Journal of Biological Chemistry 267 7402-7405.

Epstein PN, Overbeek PA \& Means AR 1989 Calmodulin-induced earlyonset diabetes in transgenic mice. Cell 58 1067-1073.

Gedulin BR, Nikoulina SE, Smith PA, Gedulin G, Nielsen LL, Baron AD, Parkes DG \& Young AA 2005 Exenatide (exendin-4) improves insulin sensitivity and $\beta$-cell mass in insulin-resistant obese fa/fa Zucker rats independent of glycemia and body weight. Endocrinology 146 2069-2076.

Gromada J, Ding WG, Barg S, Renstrom E \& Rorsman P 1997 Multisite regulation of insulin secretion by cAMP-increasing agonists: evidence that glucagon-like peptide 1 and glucagon act via distinct receptors. Pflugers Archiv 434 515-524.

Harding HP \& Ron D 2002 Endoplasmic reticulum stress and the development of diabetes: a review. Diabetes 51(Suppl 3) S455-S461.

Harrison LC, Campbell IL, Allison J \& Miller JF 1989 Mechanisms of pancreatic $\beta$-cell destruction: immune and nonimmune. In Perspectives on the Molecular Biology and Immunology of the Pancreatic $\beta$ Cell, pp 93-102. Eds D Hanahan, HO McDevitt \& GF Cahill. Cold Spring Harbor, New York: Cold Spring Harbor Laboratory.

Jhala US, Canettieri G, Screaton RA, Kulkarni RN, Krajewski S, Reed J, Walker J, Lin X, White M \& Montminy M 2003 cAMP promotes pancreatic beta-cell survival via CREB-mediated induction of IRS2. Genes and Development 17 1575-1580.

Kang G \& Holz GG 2003 Amplification of exocytosis by $\mathrm{Ca}^{2+}$-induced $\mathrm{Ca}^{2+}$ release in INS-1 pancreatic beta cells. Journal of Physiology 546 175-189.

Kulkarni RN, Roper MG, Dahlgren G, Shih DQ, Kauri LM, Peters JL, Stoffel M \& Kennedy RT 2004 Islet secretory defect in insulin receptor substrate 1 null mice is linked with reduced calcium signaling and expression of sarco(endo)plasmic reticulum $\mathrm{Ca}^{2+}$-ATPase (SERCA)-2b and -3. Diabetes 53 1517-1525.

Leon DD, Crutchlow MF, Ham JY \& Stoffers DA 2005 Role of glucagon-like peptide-1 in the pathogenesis and treatment of diabetes mellitus. International Journal of Biochemistry and Cell Biology 38 845-859.

Luque MA, Gonzalez N, Marquez L, Acitores A, Redondo A, Morales M, Valverde I \& Villanueva-Penacarrillo ML 2002 Glucagon-like peptide-1 (GLP-1) and glucose metabolism in human myocytes. Journal of Endocrinology 173 465-473.

Mandrup-Poulsen T 2003 Apoptotic signal transduction pathways in diabetes. Biochemical Pharmacology 66 1433-1440.

Montrose-Rafizadeh C, Avdonin P, Garant MJ, Rodgers BD, Kole S, Yang H, Levine MA, Schwindinger W \& Bernier M 1999 Pancreatic glucagon-like peptide-1 receptor couples to multiple $G$ proteins and activates mitogenactivated protein kinase pathways in Chinese hamster ovary cells. Endocrinology 140 1132-1140.

Oyadomari S, Araki E \& Mori M 2002a Endoplasmic reticulum stressmediated apoptosis in pancreatic beta-cells. Apoptosis $7335-345$.

Oyadomari S, Koizumi A, Takeda K, Gotoh T, Akira S, Araki E \& Mori M $2002 b$ Targeted disruption of the Chop gene delays endoplasmic reticulum stress-mediated diabetes. Journal of Clinical Investigation 109 525-532.

Park S, Dong X, Fisher TL, Dunn S, Omer AK, Weir G \& White MF 2006 Exendin-4 uses Irs 2 signaling to mediate pancreatic beta cell growth and function. Journal of Biological Chemistry 281 1159-1168.

Roe MW, Philipson LH, Frangakis CJ, Kuznetsov A, Mertz RJ, Lancaster ME, Spencer B, Worley JF III \& Dukes ID 1994 Defective glucose-dependent endoplasmic reticulum $\mathrm{Ca}^{2+}$ sequestration in diabetic mouse islets of Langerhans. Journal of Biological Chemistry 269 18279-18282. 
Scheuner D, Mierde DV, Song B, Flamez D, Creemers JW, Tsukamoto K, Ribick M, Schuit FC \& Kaufman RJ 2005 Control of mRNA translation preserves endoplasmic reticulum function in beta cells and maintains glucose homeostasis. Nature Medicine 11 757-764.

Schildberg FA, Schulz S, Dombrowski F \& Minor T 2005 Cyclic AMP alleviates endoplasmic stress and programmed cell death induced by lipopolysaccharides in human endothelial cells. Cell and Tissue Research $\mathbf{3 2 0}$ 91-98.

Sugden MC, Christie MR \& Ashcroft SJ 1979 Presence and possible role of calcium-dependent regulator (calmodulin) in rat islets of Langerhans. FEBS Letters 105 95-100.

Thorens B 1992 Expression cloning of the pancreatic beta cell receptor for the gluco-incretin hormone glucagon-like peptide 1. PNAS 89 8641-8645.

Tsunekawa S, Miura Y, Yamamoto N, Itoh Y, Ariyoshi Y, Senda T, Oiso Y \& Niki I 2005 Systemic administration of pituitary adenylate cyclaseactivating polypeptide maintains beta-cell mass and retards onset of hyperglycaemia in beta-cell-specific calmodulin-overexpressing transgenic mice. European Journal of Endocrinology 152 805-811.

Valverde I \& Malaisse WJ 1984 Calmodulin and pancreatic B-cell function. Experientia 40 1061-1068.

Varadi A, Molnar E, Ostenson CG \& Ashcroft SJ 1996 Isoforms of endoplasmic reticulum $\mathrm{Ca}^{2+}$-ATPase are differentially expressed in normal and diabetic islets of Langerhans. Biochemical Journal 319 521-527.

Varadi A, Lebel L, Hashim Y, Mehta Z, Ashcroft SJ \& Turner R 1999 Sequence variants of the sarco(endo)plasmic reticulum $\mathrm{Ca}^{2+}$-transport ATPase 3 gene (SERCA3) in Caucasian type II diabetic patients (UK Prospective Diabetes Study 48). Diabetologia 42 1240-1243.
Wang Q \& Brubaker PL 2002 Glucagon-like peptide-1 treatment delays the onset of diabetes in 8 week-old db/db mice. Diabetologia 45 1263-1273.

Yaekura K \& Yada T $1998\left[\mathrm{Ca}^{2+}\right]$ i-reducing action of cAMP in rat pancreatic beta-cells: involvement of thapsigargin-sensitive stores. American Journal of Physiology 274 C513-C521.

Yaekura K, Yanagida K \& Yada T 1998 PACAP and GLP-1 protect islet betacells against $\mathrm{Ca}^{2+}$ toxicity induced by high $\mathrm{K}^{+}$. Annals of the New York Academy of Sciences $\mathbf{8 6 5}$ 445-450.

Yu W, Niwa T, Miura Y, Horio F, Teradaira S, Ribar TJ, Means AR, Hasegawa Y, Senda T \& Niki I 2002 Calmodulin overexpression causes $\mathrm{Ca}^{2+}$-dependent apoptosis of pancreatic beta cells, which can be prevented by inhibition of nitric oxide synthase. Laboratory Investigation 82 1229-1239.

Yusta B, Baggio LL, Estall JL, Koehler JA, Holland DP, Li H, Pipeleers D, Ling Z \& Drucker DJ 2006 GLP-1 receptor activation improves beta cell function and survival following induction of endoplasmic reticulum stress. Cell Metabolism $\mathbf{4}$ 391-406.

Zhou YP, Teng D, Dralyuk F, Ostrega D, Roe MW, Philipson L \& Polonsky KS 1998 Apoptosis in insulin-secreting cells. Evidence for the role of intracellular $\mathrm{Ca}^{2+}$ stores and arachidonic acid metabolism. Journal of Clinical Investigation 101 1623-1632.

Received in final form 29 January 2007

Accepted 31 January 2007

Made available online as an Accepted Preprint

5 February 2007 